\title{
TRADUCCIÓN
}

\section{DEFINICIÓN DE ALFABETIZACIÓN INFORMACIONAL DE CILIP, 2018*}

Information Literacy Group (ILG), CILIP (The library and information association), Reino Unido.

\author{
Autoría, en orden alfabético: \\ Emma Coonan \\ Anglia Ruskin University \\ Jacqueline Geekie \\ Aberdeenshire Libraries \\ Stéphane Goldstein \\ InformAll \\ Lisa Jeskins \\ Lisa Jeskins Training
}

Rosie Jones

The Open University

Rowena Macrae-Gibson

Brunel University London

Jane Secker

City, University of London

Geoff Walton

Manchester Metropolitan University

Traducido por:

Dora Sales Salvador**

Universidad Jaume I de Castellón

Resumen: Se traduce al castellano la nueva definición de alfabetización informacional de CILIP (Reino Unido), cuyo original se publicó en 2018. Se trata de una definición con enorme potencial, que enfatiza la relevancia de la ALFIN en la sociedad actual, para todas las personas, no solo en el contexto educativo.

Palabras clave: alfabetización informacional; definición; traducción; vida cotidiana; ciudadanía; CILIP.

Title: DEFINITION OF INFORMATION LITERACY 2018.

Abstract: This is the Spanish translation of the new CILIP (United Kingdom) definition of information literacy, originally published in 2018. It is a definition with enormous potential, which enhances the relevance of IL in today's society, for all people, not only in the educational context.

Keywords: information literacy; definition; translation; everyday life; citizenship; CILIP.

Copyright: (C) 2020 Servicio de Publicaciones de la Universidad de Murcia (Spain). Este es un artículo de acceso abierto distribuido bajo los términos de la licencia Creative Commons Reconocimiento 4.0 Internacional (CC BY 4.0).

\footnotetext{
* Traducción de la definición original CILIP Definition of Information Literacy 2018, elaborada por el Information Literacy Group (ILG) de CILIP. Original disponible en: <https://infolit.org.uk/new-il-definition> (Consulta: 23 de abril de 2019). Traducción y publicación autorizada por CILIP. Para esta traducción se han revisado los enlaces incluidos en las notas al pie presentes en el documento original y se han actualizado las fechas de consulta.

** dsales@trad.uji.es

Recibido: 29-04-2019; aceptado: 23-12-2019.
}

INFORMATION LITERACY GROUP (ILG) de CILIP. Definición de alfabetización informacional de CILIP, 2018. Anales de Documentación, 2020, vol. 23, nº 1. Disponible en: http://dx.doi.org/10.6018/analesdoc.373811. 


\section{DEFINICIÓN DE ALFABETIZACIÓN INFORMACIONAL}

La alfabetización informacional es la capacidad de pensar de forma crítica y emitir opiniones razonadas sobre cualquier información que encontremos y utilicemos. Nos empodera, como ciudadanos y ciudadanas, para alcanzar y expresar puntos de vista informados y comprometernos plenamente con la sociedad.

La alfabetización informacional incluye un conjunto de habilidades y capacidades que todas las personas necesitamos para realizar tareas relacionadas con la información: por ejemplo, cómo descubrirla, acceder a ella, interpretarla, analizarla, gestionarla, crearla, comunicarla, almacenarla y compartirla. Pero es mucho más que eso: se refiere a la aplicación de las competencias, las cualidades y la confianza necesarias para utilizar la información de la mejor manera posible e interpretarla de forma juiciosa. Incluye el pensamiento crítico y la conciencia crítica, así como la comprensión de los aspectos tanto éticos como políticos relacionados con el uso de la información.

La alfabetización informacional se refiere a la información en todas sus formas: no solo la información impresa, sino también los contenidos digitales, los datos, las imágenes y la palabra hablada. La alfabetización informacional se relaciona y se solapa con otras alfabetizaciones, que incluyen específicamente la alfabetización digital (digital literacy), la alfabetización académica (academic literacy) y la alfabetización mediática (media literacy). No es un concepto independiente, y se alía con otras áreas de conocimiento y comprensión.

La alfabetización informacional ayuda a entender los aspectos éticos y legales relacionados con el uso de la información, incluyendo la privacidad, la protección de datos, la libertad de información, el acceso abierto/los datos de libre acceso y la propiedad intelectual. De manera importante, la alfabetización informacional es empoderadora y supone una contribución fundamental para las sociedades democráticas, inclusivas y participativas; tal y como la entiende la UNESCO, es un derecho humano universal.

\section{CONTEXTOS}

\subsection{Alfabetización informacional y vida cotidiana}

La alfabetización informacional puede emplearse en la vida cotidiana sin que las personas se den cuenta de que la están utilizando - por ejemplo, consultando las reseñas sobre un hotel en páginas web de reseñas de viajes o comparando las opciones de diversas pólizas de seguros. También concierne a la comprensión respecto a las limitaciones de estos recursos en internet, cómo pueden ser objeto de manipulación y la necesidad de saber distinguir su importancia.

Asimismo, la alfabetización informacional también es relevante cuando se realizan transacciones en línea, pues es necesario tomar conciencia de las medidas de seguridad en internet. Las habilidades de pensamiento crítico son esenciales para evitar estafas en internet y por teléfono, y para protegerse de las transacciones fraudulentas.

La alfabetización informacional ayuda a las personas a comportarse de forma ética en sus actividades en internet, permitiéndoles ser conscientes de la información que utilizan y comparten sobre sí mismas y sobre otras personas en todo tipo de plataformas en línea, incluyendo las redes sociales.

Esto implica también la comprensión del concepto de "huella digital", es decir, los rastros que dejan las personas a medida que consumen y crean información. La alfabetización informacional proporciona a las personas estrategias para gestionar su identidad en línea y darle forma de manera que se sientan cómodas con ella, teniendo en cuenta aspectos de privacidad y seguridad personal sobre sí mismas y sobre otras personas.

\subsection{Alfabetización informacional y ciudadanía}

La alfabetización informacional permite que las personas adquieran y desarrollen su comprensión del mundo que les rodea; que lleguen a conocer puntos de vista informados; que, cuando sea apropiado, desafien con credibilidad y de manera informada las suposiciones y las ortodoxias (incluyendo la propia), e incluso la autoridad; que reconozcan los sesgos y la desinformación; y que, de ese modo, sean ciudadanos y ciudadanas comprometidos, capaces de participar plenamente en la vida democrática y en la sociedad. La alfabetización informacional ayuda a abordar la exclusión social, al proporcionarles a los grupos desfavorecidos o marginalizados los medios para que le den sentido al mundo que les rodea y participen en la sociedad.

En un contexto global en el que fake news (noticias falsas) se ha convertido en un término aceptado, la capacidad de mostrar una perspectiva crítica respecto a múltiples fuentes de información, especialmente en línea, es crucial. Ya 
sea en relación con los medios de comunicación convencionales, las redes sociales, las búsquedas en internet o tan solo la información que se comunica verbalmente, la alfabetización informacional ayuda a las personas a formarse opiniones sobre la fiabilidad y la autoridad de las fuentes de información. De este modo, también, la alfabetización informacional refuerza el compromiso democrático y cívico. La alfabetización informacional, junto con la alfabetización mediática (media literacy), es la base del periodismo ético.

\subsection{Alfabetización informacional y educación}

La alfabetización informacional es aplicable a todas las etapas del aprendizaje, formal e informal, abarcando la etapa escolar (primaria y secundaria), la educación complementaria (further education, FE), ${ }^{1}$ la educación superior y, de manera crucial, la educación a lo largo de la vida. La alfabetización informacional no termina con la educación formal.

La alfabetización informacional puede mejorar y enriquecer diversas asignaturas que se imparten en los planes de estudio escolares, si se incorpora como parte de las habilidades de pensamiento crítico y desarrollo del conocimiento.

Tiene especial relevancia para el estudiantado implicado en el aprendizaje basado en la investigación, como por ejemplo el estudiantado matriculado en el Bachillerato Internacional ${ }^{2}$ y en el Extended Project Qualification (EPQ), ${ }^{3}$ que implica la realización de un trabajo amplio sobre un tema elegido por el estudiantado y supervisado por el profesorado. La alfabetización informacional también ayuda al estudiantado a abrirse camino en la transición desde la escuela hasta la educación complementaria y la educación superior.

En la educación superior, la alfabetización informacional contribuye a las competencias académicas, las metodologías de investigación y la comprensión respecto a lo que es el plagio. Al igual que la ACRL (Association of College and Research Libraries), ${ }^{4}$ consideramos la formación en alfabetización informacional como una serie de "conceptos umbral" que permiten que el estudiantado descubra nuevas formas de pensar y nuevos conocimientos. La alfabetización informacional está en la base de las habilidades transferibles y de empleabilidad, preparando al estudiantado como parte del aprendizaje a lo largo de la vida. En entornos educativos formales, la alfabetización informacional puede considerarse como la capacidad crítica para leer entre líneas. Permite que el estudiantado participe en un aprendizaje profundo: aprender a percibir las relaciones entre ideas importantes, hacer preguntas novedosas y buscar líneas de razonamiento innovadoras.

Esta forma activa y crítica de aprendizaje anima al alumnado y al estudiantado a dominar con rapidez los elementos fácticos y descriptivos del contenido ("Qué” y “Cómo") y después pasar a investigar aspectos de un nivel superior, como la fuente de información, el grado de autoridad, la posibilidad de que haya sesgos y qué significa en el contexto más amplio. Está en sintonía, por ejemplo, con el objetivo del English National Curriculum ${ }^{5}$ en cuanto a preparar al estudiantado "para hacer preguntas perspicaces, pensar de forma crítica, sopesar las pruebas, cribar los argumentos y desarrollar la perspectiva y la opinión". 6

De manera importante, la alfabetización informacional dota al alumnado en todos los niveles de estrategias y herramientas intelectuales, como por ejemplo la elección de un enfoque inquisitivo, no solo para resolver problemas sino también para encuadrar los problemas y las situaciones de formas nuevas e innovadoras. Esta competencia es crucial, más allá de la educación, para satisfacer las expectativas del lugar de trabajo. ${ }^{7}$

\subsection{Alfabetización informacional y el lugar de trabajo}

En el lugar de trabajo, la alfabetización informacional consiste en saber cuándo y cómo utilizar la información para ayudar a alcanzar los objetivos de la organización, y añadir valor a las actividades de la organización. Esto resulta aplicable independientemente de la escala y la ubicación del lugar de trabajo, y de si el contexto de trabajo es el sector comercial, público o sin ánimo de lucro.

La naturaleza exacta de la alfabetización informacional depende en gran medida del contexto del lugar de trabajo, y refleja la cultura, las prácticas y las experiencias del lugar de trabajo.

Como tal, puede manifestarse de múltiples formas, reflejando la rica variedad de contextos en los que se aplica. La alfabetización informacional ayuda a interpretar la información relacionada con el trabajo, a compartirla (dentro de las organizaciones y con partes externas interesadas, como clientes o consumidores/as) y a transformarla en conocimiento. La alfabetización informacional significa trabajar de forma ética, comprendiendo las implicaciones de la protección de datos, y los derechos de propiedad intelectual, como el copyright. 
La alfabetización informacional también se manifiesta tanto en lo relativo al comportamiento informacional individual de los trabajadores y las trabajadoras como en las políticas, estrategias y actividades corporativas de las organizaciones. Puede quedar subsumida en otros conceptos relacionados con el empleo, como la gestión del conocimiento y de la información, y la gestión de datos. También contribuye a la empleabilidad al apoyar cualidades que son ampliamente reconocidas por quienes realizan la selección del personal, como el trabajo en equipo, la resolución de problemas y las habilidades de análisis.

\subsection{Alfabetización informacional y salud}

La alfabetización informacional, en ocasiones conocida en este sentido como alfabetización en salud, ayuda a tomar decisiones informadas relacionadas con la salud y el bienestar de las personas y sus familias. Para las personas y sus cuidadores/as es vital encontrar fuentes de información fiables para gestionar los problemas de salud, la prevención y el envejecimiento.

Esto implica utilizar fuentes de atención sanitaria fidedignas y acreditadas al buscar tratamiento y pronóstico. Para ser partícipes activos en su atención sanitaria, los/las pacientes se benefician de la alfabetización en salud, que les permite entablar un diálogo informado con los/las profesionales sanitarios/as.

\section{EL PAPEL DE LOS/LAS PROFESIONALES DE LA INFORMACIÓN}

Los/las profesionales de la información desempeñan un papel crucial en la defensa, el apoyo y la promoción de la alfabetización informacional. Esto puede ser más evidente en contextos educativos en los que el personal de la biblioteca universitaria imparta formación al estudiantado o el personal de la biblioteca escolar colabore en el aprendizaje basado en la investigación o en las metodologías de proyectos de investigación. El personal de las bibliotecas públicas da apoyo a los diversos usos de la alfabetización informacional en la vida cotidiana, en escenarios tanto formales como informales, y tal vez tiene una de las mayores responsabilidades al prestar apoyo a la amplia variedad de necesidades de alfabetización informacional del público en general. Los/las profesionales de la información en salud, incluyendo al personal de bibliotecas sanitarias, tienen un papel clave al proporcionar e interpretar información y pruebas para los/las médicos, y garantizar que el personal sanitario, los/las pacientes y el público tengan acceso a información precisa, que cambia la vida.

La alfabetización informacional es fundamental para los/las profesionales de la información, ya que crean, conservan y posibilitan el uso de diversos tipos de información de manera ética.

Otras figuras profesionales, como docentes, asesores/as académicos/as y tecnólogos/as de la educación también fomentan la alfabetización informacional, y es fundamental que los/las profesionales de la información trabajen en colaboración con estas figuras.

La formación y el apoyo a los/las profesionales de la información en lo que respecta a la alfabetización informacional se puede proporcionar a través de diversas rutas, que incluyen, pero no se limitan a:

- Másteres en Biblioteconomía y Documentación

- Becas para estudios de Higher Education Academy ${ }^{8}$

- Cursar la formación proporcionada por el grupo de alfabetización informacional (Information Literacy Group) de CILIP, incluyendo LILAC ${ }^{9}$

- Recursos disponibles en la web de alfabetización informacional ${ }^{10}$

- Lecturas profesionales

- Apoyo de otros/as compañeros/as

- Otras fuentes de formación profesional.

\section{CONTEXTO}

El grupo de alfabetización informacional (Information Literacy Group) de CILIP ha creado esta definición ${ }^{11}$ de alfabetización informacional para actualizar la definición elaborada por CILIP en 2004. La teoría y la práctica de la alfabetización informacional han evolucionado considerablemente desde entonces, y la nueva definición refleja esta evolución, especialmente al abordar la relevancia de la alfabetización informacional más allá de la educación formal. La nueva definición también se dirige a audiencias múltiples, potencialmente a cualquiera que utilice y maneje información, y no solo a los/las profesionales de la información. 
La Declaración de Alejandría, de la UNESCO, ha inspirado algunas de las ideas en las que se basa este trabajo, que también se inspira en el actualizado Framework for Information Literacy de ACRL y en el A New Curriculum for Information Literacy (ANCIL). ${ }^{12}$

"La alfabetización informacional empodera a las personas en todos los ámbitos de la vida para buscar, evaluar, usar y crear información de manera eficaz para lograr sus metas personales, sociales, ocupacionales y educativas. Es un derecho humano básico en el mundo digital y promueve la inclusión social en todas las naciones".

UNESCO (2005) Declaración de Alejandría

\section{¿CÓMO SE CONCIBIÓ?}

En junio de 2016, el Comité del ILG (Information Literacy Group, grupo de alfabetización informacional) lanzó una consulta a los/las miembros del ILG. ${ }^{13}$ Quienes respondieron aportaron ideas útiles sobre la manera en que se podría abordar la tarea. En agosto y septiembre se solicitaron comentarios adicionales a los/las propios/as miembros del Comité y luego se obtuvo retroalimentación adicional en el Congreso LILAC celebrado en abril de 2017. El resultado de estas consultas es un marco recomendado, y a continuación se expone la dimensión de su alcance para una definición ampliada. La definición se completó en agosto de 2017 y fue aprobada en la reunión del Comité del ILG el 1 de septiembre de 2017. La Junta Directiva de CILIP aprobó la definición en noviembre de 2017.

Abril 2018

1 Nota de la traductora: Parte del sistema educativo del Reino Unido. Véase: < http://www.universia.es/estudiar-extranjero/reino-unido/sistemaeducativo/estructura-sistema-educativo/193> (Consulta: 23 de abril de 2019).

${ }^{2}$ El Bachillerato Internacional es un programa educativo para estudiantado de 3 a 19 años, que se centra en enseñar al estudiantado a pensar de forma crítica e independiente, y a investigar con cuidado y lógica. Se imparte en más de 5000 centros de más de 150 países, incluyendo el Reino Unido (Nota de la traductora: y España). Más información en: <http://www.ibo.org/> (Consulta: 23 de abril de 2019).

${ }^{3}$ Se trata de un título independiente que a menudo cursa el estudiantado como complemento a sus estudios en los últimos dos años de la enseñanza secundaria (A Level). El EPQ ayuda al estudiantado a desarrollar y demostrar sus habilidades para la gestión de proyectos y le proporciona oportunidades para ampliar su competencia para la redacción extensa (extended writing). Más información en: $<$ https://qips.ucas.com/qip/extendedproject-qualification-epq> (Consulta: 23 de abril de 2019). Nota de la traductora: Tanto el EPQ como la extended writing son propios del sistema educativo del Reino Unido.

4 ACRL (2016) Framework for Information Literacy for Higher Education. Disponible en: < http://www.ala.org/acrl/standards/ilframework> (Consulta: 23 de abril de 2019). Nota de la traductora: Revisión de la traducción al castellano. Marco de referencia para la alfabetización informacional en la educación superior, a cargo de Dora Sales (Universitat Jaume I), 2019.2 Doi: $<$ http://dx.doi.org/10.6035/2019.MarcoAlfabetizacion>.

${ }^{5}$ Nota de la traductora: Directrices oficiales para los planes de estudios en el sistema educativo británico. Véase la nota siguiente, incluida en el documento original de CILIP.

${ }^{6}$ Department for Education (2013) National curriculum in England: history programmes of study. Disponible en:

$<$ https://www.gov.uk/government/publications/national-curriculum-in-england-history-programmes-of-study/national-curriculum-in-englandhistory-programmes-of-study> (Consulta: 23 de abril de 2019).

${ }^{7}$ Head, A.J. Posing the million-dollar question: What happens after graduation? Journal of Information Literacy, 2017, vol. 11, n ${ }^{\circ}$ 1, p. 80-90. DOI: $<$ https://doi.org/10.11645/11.1.2186>.

8 Nota de la traductora: Institución británica que promueve la excelencia en la educación superior. Véase: <https://www.heacademy.ac.uk/> (Consulta: 23 de abril de 2019).

${ }^{9}$ Nota de la traductora: LILAC es el congreso anual sobre alfabetización informacional organizado por el Information Literacy Group (ILG) de CILIP. Véase: <https://www.lilacconference.com/> (Consulta: 23 de abril de 2019).

10 Nota de la traductora: Web sobre alfabetización informacional gestionada por el Information Literacy Group (ILG) de CILIP. Véase: $<$ https://infolit.org.uk/> (Consulta: 23 de abril de 2019).

${ }^{11} \mathrm{La}$ definición actual y la declaración de apoyo pueden encontrarse en: <http://www.cilip.org.uk/cilip/advocacy-campaigns-awards/advocacycampaigns/information-literacy/information-literacy> (Consulta: 23 de abril de 2019).

12 Secker, Jane y Coonan, Emma (2011) A New Curriculum for Information Literacy (ANCIL). Disponible en: $<$ https://newcurriculum.wordpress.com> (Consulta: 23 de abril de 2019).

13 Actualmente el ILG cuenta con alrededor de 1.500 miembros. 